\title{
Potassium solubilization: Strategies to mitigate potassium deficiency in agricultural soils
}

\author{
Vijay Singh Meena 1,2*, Bihari Ram Maurya ${ }^{2}$, Sunita Kumari Meena ${ }^{3}$, Pankaj Kumar \\ Mishra ${ }^{1}$, Jaideep Kumar Bisht ${ }^{1}$ and Arunava Pattanayak ${ }^{1}$
}

1 Department of ICAR-Vivekananda Parvatiya Krishi Anusandhan Sansthan (VPKAS), Almora 263601, Uttarakhand, India 2 Department of Soil Science and Agricultural Chemistry, Institute of Agricultural Sciences, Banaras Hindu University (BHU), Varanasi 221005, Uttar Pradesh, India 3 Division of Soil Science and Agricultural Chemistry, ICAR-Indian Agriculture Research Institute (IARI), New Delhi 110012, India.

\begin{abstract}
In soil system, 90\%-98\% $\mathrm{K}$ reserves are non-exchangeable mineral sources and potassium solubilizing microbes (KSMs) can effectively dissolve this mineral. Nowadays focused research on efficient KSMs was started. These microbes are able to enhanced their root colonization and improve plant growth and development. They solubilize K-minerals through different mechanisms including chelation, acidolysis, lowering of $\mathrm{pH}$, exchange reaction, complexation, biofilm formation and secretion of organic acid and polysaccharides. Bio-priming of seed/root through efficient KSMs resulted higher crop productivity, potassium use efficiency (KUE) and mitigate the K-deficiency in soils. In this article we are trying to summarize the KSMs current state of knowledge in agricultural crops. We highlighted the knowledge gaps and suggest future prospective of research, with hope that the use of KSMs in agricultural soil improved soil sustainability.
\end{abstract}

Citation: Meena SV, Maurya BR, Meena SK, Mishra PK, Bisht JK and Pattanayak A (2018) Potassium solubilization: Strategies to mitigate potassium deficiency in agricultural soils, GJBAHS 7: 3. doi:

Received: September 07, 2018; Accepted: September 18, 2018; Published: September 25, 2018

Copyright: (C2018 Meena, et al. This is an open-access article distributed under the terms of the Creative Commons Attribution License, which permits unrestricted use, distribution, and reproduction in any medium, provided the original author and source are credited.

Competing interests: The authors have declared that no competing interest exist.

Sources of funding: No funding.

*Email: vijay.meena@icar.gov.in

\section{Keywords:}

K-solubilization, Agriculture sustainability, Chemical fertilizer

\section{Introduction}

\section{Origin of the problems}

Nowadays increasing cost of agrochemicals, injudicious application fertilizers and lesser nutrient use efficiency (NUE) enhanced soil degradation. This necessitates development or formulation of alternate ecofriendly fertilizers [1]. A graded agroecosystem causes decline in soil-plant microbial diversity and influences environmental sustainability [2]. Soil system is a storehouse of nutrients and energy for soil-plant-microbes continuum (Figure 1). Among the micro-elements potassium is the third important macronutrient for plant nutrition that plays significant role in plant growth and development [3]. Only 2\% potassium from applied was available for the utilization of crop in soil system the rest were fixed, leaching and erosion.

A diversity of $\mathrm{KSMs}$ is involved in K-mineral (90-98\%) as orthoclase, muscovite, feldspar, biotite, mica, illite (McAfee [4]). Soil minerals accounted $98 \%$ in fixed form of total $\mathrm{K}[5]$ and only $\sim 2 \% \mathrm{~K}$ is bioavailable for plant uptake. An efficient rhizospheric microbe enhances the bioavailability of $\mathrm{K}$ from soil minerals [6]. Non-exchangeable potassium found (1\%-10\%) and consists predominantly under the interlayer $\mathrm{K}$ of nonexpanded clay minerals such as illite and lattice $\mathrm{K}$ in K-feldspars that contributed to crop [7]. Slow release of non-exchangeable $\mathrm{K}$ to exchangeable 
form occurs when the exchangeable level and solution $\mathrm{K}$ was decreased by crop removal, runoff, erosion/leaching [6].

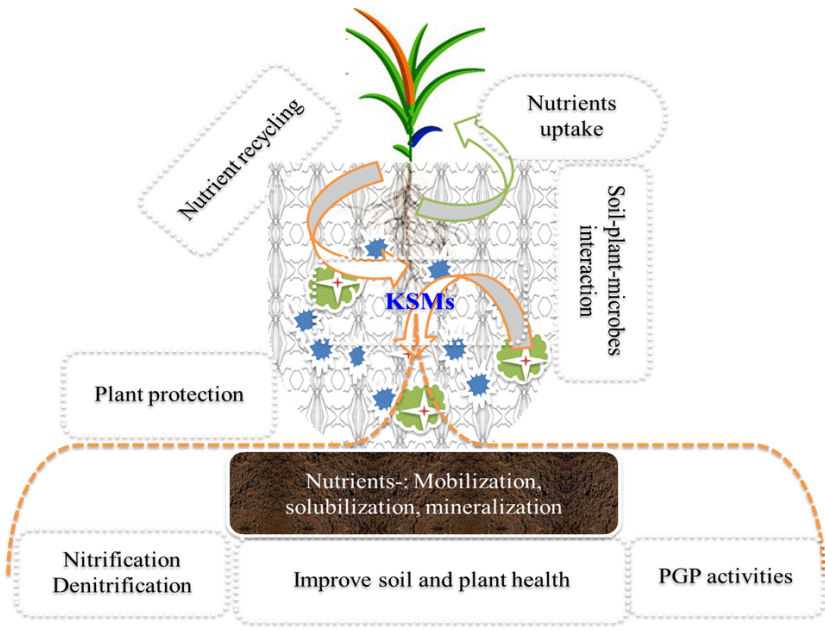

Figure 1: Plant-soil-potassium solubilizing microbe nexus.

These efficient KSMs are crucial of sustainable agricultural ecosystems. Most important KSMs are Aspergillus, Penicillium, Azotobacter, Bacillus, Pseudomonas, Arthrobacter, Thiobacillus, Clostridium, Frateuria, Burkholderia, Glomus, Agrobacterium, Rhizobium, Flavobacterium species. Phosphorous and zinc solubilizing microbes/SMART-microbes, which are ecofriendly and environmentally safe. Nowadays application efficient indigenous KSMs for crop improvement, environmental protection and soil sustainability have been a focused [6]. The diversity of KSMs is one of the crucial factors that govern the ecosystem functioning. This may be argued that the greater diversity of microbes in ecosystems could establish a functional equilibrium, which may facilitate an evergreen agriculture [8]. Hence, importance to explore the role of KSMs and their processes in the release of fixed $\mathrm{K}$ in relation to mitigate the $\mathrm{K}$ deficiency [1].

\section{Anticipated corrective tools}

Aim of sustainable agriculture is to develop efficient technologies that ensure food security, quality and environmental sustainability [2]. Potassium solubilization is a emerged out as one of viable microbial technologies for mitigating the $\mathrm{K}$ deficiency in agricultural soils [6]. These efficient microbes not only solubilize/mineralize $\mathrm{K}$ but also produce plant growth promoting substances. Few information were available on the mechanisms of K-solubilization. Potassium solubilization efficiency varies according to the nature of the Kbearing minerals [9].

Efficient rhizospheric microbes (ERMs) have the higher ability to solubilized mineral sources. This involved the adsorption of $\mathrm{K}^{+}$on to sites in the inter-layers of silicate minerals, such as illite, vermiculite and montmorillonite K-solubilization accompanied by acidolysis as well as complexolysis exchange reaction [7,9]. The Ksolubilization through KSMs was studied by various researchers repeatedly (Figure 2). They solubilize K-minerals through different mechanisms including (i) polysaccharides secretion, (ii) biofilm formation, (iii) chelation, (iv) acidolysis, (v) organic acid production, (vi) lowering of $\mathrm{pH}$, and (vii) exchange reaction $[2,10]$; The rhizosphere is the close vicinity of the root surface, that affected by root exudates. Thus, the uses of KSMs as Kbiofertilizers in crop, it reduced the use of agrochemicals and support ecofriendly agriculture [2]. Therefore, it is imperative to isolate efficient KSMs to enrich the pool of K-solubilizers species and genes as K-biofertilizers, which will be of great benefit to ecofriendly agriculture. The improvement in KSMs diversity may bring several direct and indirect mechanisms in the soil biological environment [11]. Bio-primed seed may serve as an important means of managing many soil and seed borne diseases as well as enhanced NUE [12].

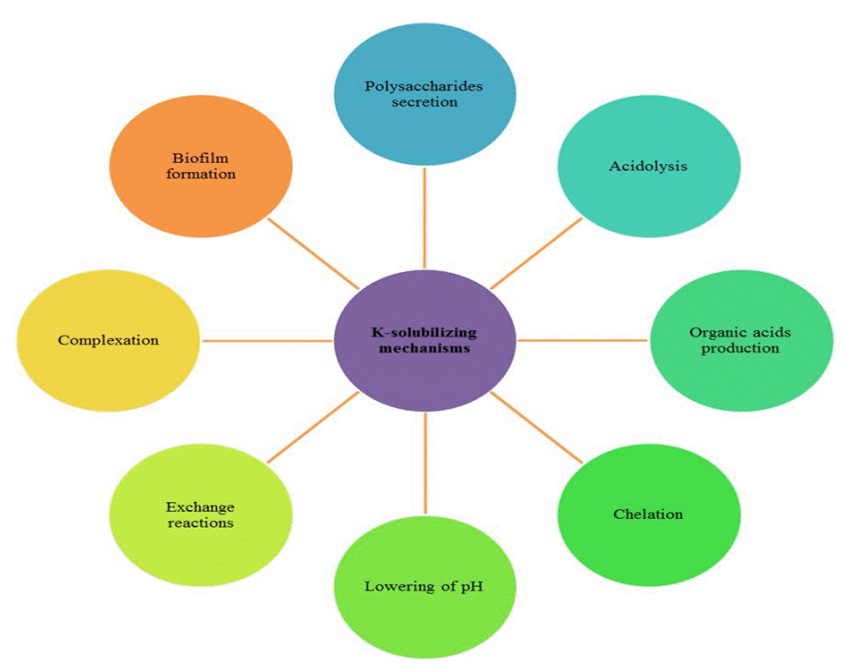

Figure 2: K-solubilizing mechanisms in soil system.

Identifying and understanding the potential influences of the anticipated climate variables on KSM efficiency towards enhance the potassium use efficiency (KUE) of ecosystem. EnvironmentalKSMs nexus and ecosystem processes remain 
unclear, and an emerging field of research has begun to investigate the utility of KSM data for improving predictions of $\mathrm{K}$ cycling beyond estimates based solely on environmental data [8]. It was confirmed from the above discussion that KSM biodiversity is one of the precious bio-resources, which can mitigate the K-deficiency in agricultural soils. However, experimental evidence at the field level is inadequate. A grouping of awareness on ecological, biochemical, physiological, microbiological mechanisms and field engineering designs would be an essential element for successful utilization of microbes in the enhancement of KUE in the disturbed ecosystem

\section{Future Prospective}

Based on our mini-review of the existing literature, it was confirmed that there is a urgent need to overcome current research gaps (i) Indoor and field studies should be focused (ii) Need for molecular studies using indigenous efficient KSMs (iii) Need for research on different crops $\times$ KSMs strains (iv) Need for research on multi-nutrients solubilization $\times$ KSMs strains (v) Need to optimize inoculation methodologies i.e. seedling, seed, soil application etc. (vi) Need to optimized K-solubilization under soil-plant-microbes system. To fulfill the mentioned limitations, there is a need for the scientific community to develop low cost methods for measuring all relevant properties under soil-pantmicrobes system in order to fulfill these requirements, especially in developing countries.

\section{Concluding Remark}

Improving the reliability and responses of KSMs strains on crop production is a timely need due to expected increase in the price of synthetic fertilizers, and environmental concerns related to uses. Diversity of efficient KSMs could be of prime importance in achieving the goals of sustainable agriculture under changing climatic scenario. The improvement in diversity of KSMs by direct uses of efficient KSMs may successfully enhance the Kavailability within a short duration through positive interactions. Further exploration and exploitation of unidentified KSMs are anticipated to increase the possibility of their use in improving K-availability leading to agricultural, environmental and economic sustainability.

\section{Acknowledgement}

This work is based upon doctoral thesis of VSM (PS-11076). We also acknowledge to the Department of Soil Science and Agricultural Chemistry, Institute of Agricultural Sciences, Banaras Hindu University and ICAR-VPKAS, Almora for give the direction and suggestion for this type research works which is more important for sustainable agriculture.

\section{References}

1. Meena SK, Rakshit A, Meena VS. Effect of seed biopriming and $\mathrm{N}$ doses under varied soil type on nitrogen use efficiency (NUE) of wheat (Triticum aestivum L.) under greenhouse conditions. Biocatal Agric Biotechnol. 2016;6:68-75.

2. Singh JS. Microbes: The chief ecological engineers in reinstating equilibrium in degraded ecosystems. Agric. Ecosyst Environ. 2015;203:80-82.

3. Rehm G, Schmitt M. Potassium for crop production. University of Minnesota Extension. 2002;46:229-236.

4. McAfee J. Potassium, a key nutrient for plant growth, department of soil and crop sciences. 2008:1.

5. Sparks DL. Potassium dynamics in soils. Advn Soil Sci. 1987;6:1-63

6. Meena VS, Maurya BR, Verma JP, Aeron A, Kumar A, Kim K, et al. Potassium solubilizing rhizobacteria (KSR): Isolation, identification, and K-release dynamics from waste mica. Ecol Eng. 2015:81:340-347.

7. Zhang C, Kong F. Isolation and identification of potassium-solubilizing bacteria from tobacco rhizospheric soil and their effect on tobacco plants. Applied Soil Ecol. 2014;82:18-25.

8. Meena VS, Maurya BR, Verma JP. Does a rhizospheric microorganism enhance $\mathrm{Ka}^{0}$ availability in agricultural soils? Microbiol Res. 2014:169:337-347.

9. Uroz S, Calvaruso C, Turpault MP, Frey-Klett P. Mineral weathering by bacteria: ecology, actors and mechanisms. Trends Microbiol. 2009;17:378-387.

10. Zarjani JK, Aliasgharzad N, Oustan S, Emadi M, Ahmadi A. Isolation and characterization of potassiumsolubilizing bacteria in some Iranian soils. Arch Agrn Soil Sci. 2013;59:1713-1723.

11. Zörb C, Senbayram M, Peiter E. Potassium in agriculture--status and perspectives. J Plant Physiol. 2014;171:656-669.

12. Meena VS, Meena SK, Verma JP, Kumar A, Aeron A, Mishra PK, et al. Plant beneficial rhizospheric microorganism (PBRM) strategies to improve nutrients use efficiency: A review. Ecol Eng. 2017:107:8-32. 